Kaur Alttoa

\title{
ANMERKUNGEN ZUR BAUGESCHICHTE DER ST. OLAIKIRCHE AUF WORMS (VORMSI) IM BISTUM ÖSEL-WIEK (SAARE-LÄÄNE)
}

Worms ist eine kleine Insel, die etwas nördlich vom Schifffahrtsweg zwischen Hapsal (Haapsalu) und der Insel Dagö (Hiiumaa) liegt. Im Mittelalter gehörte Worms zum Bistum Ösel-Wiek. Bis zum 2. Weltkrieg wurde die Insel von Schweden bewohnt. Hier liegt auch die Kirche, die dem Heiligen Olaf, König von Norwegen, geweiht war, der zweifelsohne unter den Skandinaviern den populärsten Heilige darstellte. Der Archäologe Jonathan Lindström, dessen Wurzeln nach Worms zurückführen, hat eine umfangreiche Forschungshypothese vorgelegt, dass die Insel im Jahr 1206 von Familien, die von der Insel Öland stammten, besiedelt wurde. ${ }^{1}$ Es handelt sich um eine sehr überzeugende These, der wohl vorläufig noch der archäologische Beleg fehlt. Gleichzeitig verdient die in der Nachbarschaft von Worms liegende Halbinsel Nuckö (Noarootsi) unsere Aufmerksamkeit, denn sie war im Mittelalter eine Insel. Die in den Jahren 1998-2001 erfolgten archäologischen

DOI: https://doi.org/10.12697/BJAH.2017.14.01

Übersetzung aus dem Estnischen von Marju und Olaf Mertelsmann.

Die Anregung zum Verfassen dieses Aufsatzes gab die von Juhan Maiste und Anu Ormisson-Lahe organisierte Exkursion für Magisterstudenten der Kunstgeschichte auf die Insel Worms im Jahr 2014. Der Autor dankt Ivar Rüütli und Jonathan Lindström für die Vermittlung von Materialien über die frühe Geschichte der Insel.

1 Jonathan Lindström, Biskopen och korståget 1206: om krig, kolonisation och Guds man i Norden (Stockholm: Norstedts, 2015). 


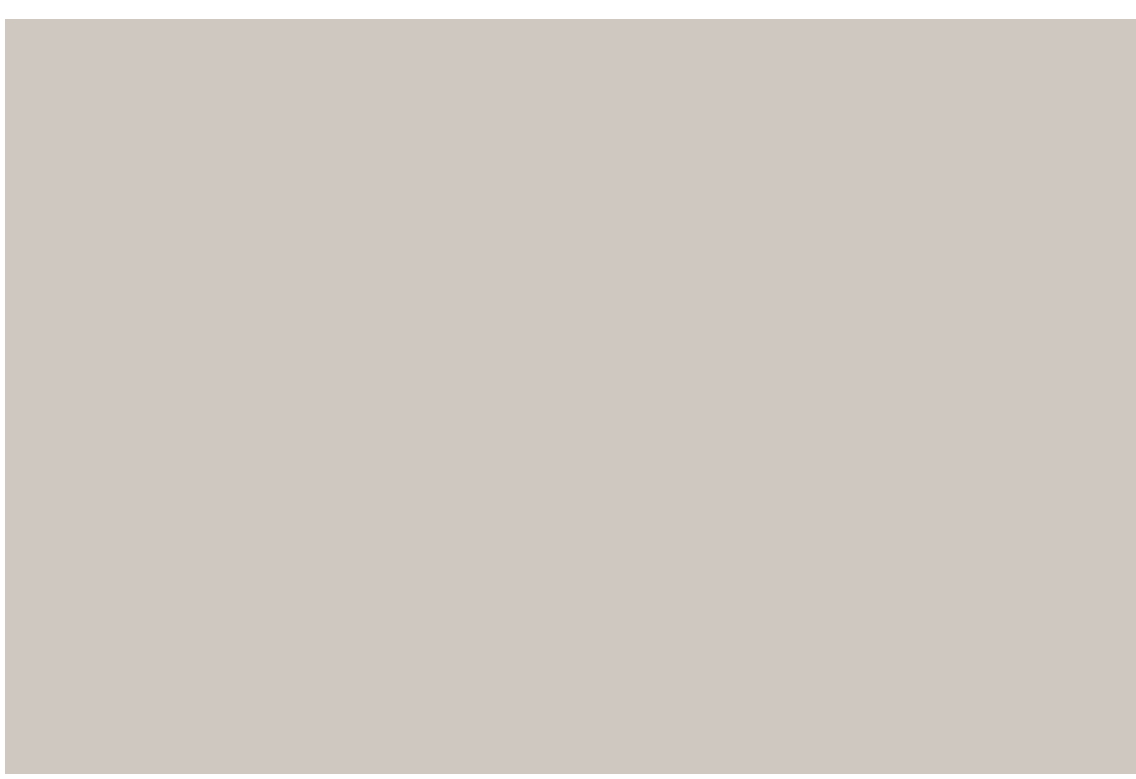

Abb. 1. St. Olai auf Worms. Foto von Kaur Alttoa.

Ausgrabungen zeigten, dass dieses Gebiet wahrscheinlich schon vor der Eroberung des Baltikums im 13. Jahrhundert von Schweden besiedelt war - möglicherweise sogar bereits vor dem 10. Jahrhundert. ${ }^{2}$ Damit sollte zumindest hypothetisch die Möglichkeit berücksichtigt werden, dass Worms vor dem Jahr 1206 keine insula deserta war und dass ebenfalls wie im Falle Nuckös schon skandinavische Siedlungen vor der Eroberung und Christianisierung Estlands in den ersten Jahrzehnten des 13. Jahrhunderts auf Worms entstanden waren.

\section{FORSCHUNGSGESCHICHTE}

Im ausgesprochen reichhaltigen und spannenden architektonischen Erbe Estlands finden sich zahlreiche Gebäude, die nur beiläufig die Architekturhistoriker beschäftigt haben. Eines von ihnen ist die Kirche auf Worms. Die bis jetzt umfangreichste Untersuchung über diese Kirche hat im Jahr 1937 Sten Karling veröffentlicht, ${ }^{3}$ der einige

2 Felicia Markus, „Field investigations in Einbi, an Estonian Swedish village“, Eesti Arheoloogia Ajakiri, 6 (2) (2006), 109-133, besonders 127-128.

3 Sten Karling, Vormsö kyrka (Haapsalu: [Haapsalu Ühistrükikoda], 1937).
Jahre zuvor, nämlich 1933, zum Professor für Kunstgeschichte der Universität Dorpat (Tartu) gewählt worden war. Wohl sind viele in dieser Arbeit vertretenen Standpunkte inzwischen veraltet. Die Frage besteht nicht in der Professionalität des damals jungen Kunsthistorikers. Das Problem liegt vielmehr darin, dass damals die Erforschung der mittelalterlichen Sakralarchitektur Estlands in ihren Anfängen stand. ${ }^{4}$ Liefern wir hier ein Beispiel. Bei der Untersuchung mittelalterlicher Architektur muss beim Fehlen von schriftlichen Angaben häufig die vergleichende Methode genutz werden. Dies machte auch Karling und er fand gemeinsame Züge des Chorraums der Olaikirche mit der Heiliggeistkirche (Pühavaimu kirik) in Reval (Tallinn) und den Kirchen zu Kegel (Keila) und Kreuz (Risti). Nur waren die Informationen über diese Kirchen damals begrenzt und äußerst fragwürdig - die ersten wesentlichen wissenschaftlichen Untersuchungen erschienen erst Jahrzehnte später. ${ }^{5}$ So erscheint es auch als verständlich, dass Karlings genanntes Werk heutzutage vor allem historiografisches Interesse weckt. Auf Karlings Ansichten stützt sich auch der Abschnitt in der 1965 erschienenen "Geschichte der estnischen Architektur", der St. Olai auf Worms behandelt. ${ }^{6}$ Die bis jetzt einzige wesentliche architekturhistorische Publikation zu dieser Kirche ist Villem Raams Kurzartikel im Sammelband „Estnische Architektur “. ${ }^{7}$ Im Jahr 1988 verfasste dieser Forscher auch einen Überblick in Manuskriptform über die Baugeschichte der Kirche auf Worms. ${ }^{8}$

4 Eine ähnliche Situation bestand auch bezüglich der Untersuchung der älteren Kunst. Karling behandelt in seinem Buch auch das barocke Interieur der Kirche (Karling, Vormsö kyrka, 11-19). Auch hier finden Sich mehrere Ansichten, die der Forscher selbst in seinen späteren Arbeiten erheblich korrigiert hat. 1938. Akadeemilise Rootsi-Eesti Seltsi Gabriel de la Gardie som byggherrar i Estland“, Svio-Estonica Holzschnitzerei und Tischlerkunst der Renaissance und des Barocks in Estland. Verhandlungen de Gelehrten Estnischen Gesellschaft XXXIV (Dorpat: K. Mattiesen, 1943), 216-220, 250-251.

5 Mai Lumiste, Pühavaimu kirik (Tallinn: Eesti Raamat, 1971); Villem Raam, „Arhitektuuri- ja kunstimälestised“", Harju rajooni ajaloo- ja kultuurimälestised (Tallinn: Eesti Raamat, 1988), 67-74, 87-93.

6 Voldemar Vaga, „Kirikud ja kloostrid“, Eesti arhitektuuri ajalugu (Tallinn: Eesti Raamat, 1965), 127 7 Villem Raam, ,Vormsi Olevi kirik“, Eesti arhitektuur 2. Läänemaa, Saaremaa, Hïumaa, Pärnumaa, Viljandimaa (Tallinn: Valgus, 1996), 41-42.

8 Villem Raam, Vormsi kiriku ajalooline õiend (Tallinn, 1988). Das Manuskript befindet sich im Archiv des Amtes für Denkmalschutz [Muinsuskaitseameti arhiiv], A-2036. 


\section{HISTORISCHE ANGABEN}

August Wilhelm Hupel schreibt über St. Olai: „Die Kirche ist alt, und soll bereits 1219 vom dänischen König Waldemar II erbaut seyn.“9 Diese Geschichte wurde angeregt durch David Dubbrechs, von einer Kirchenvisitation des Jahres 1596 stammenden Informationen, dass nämlich der König von Dänemark die Kirche errichtet habe - wobei der Name des Königs und das Datum nicht erwähnt werden. ${ }^{10}$ Die erwähnten Ergänzungen wurden später im Verlauf des Umschreibens der Visitationsprotokolle - wahrscheinlich im Jahr 1696 - hinzugefügt. ${ }^{11}$ Offenbar gehören diese Angaben ins Reich der Märchen. Zweifelsohne versuchten die Dänen am Anfang des 13. Jahrhunderts einen Teil Estlands zu erbeuten, so wurde 1206 ein Kriegszug nach Ösel (Saaremaa) durchgeführt, der aber erfolglos endete. Im Jahr 1219 aber eroberten die Truppen König Waldemars II. Reval. Darauf folgte die Christianisierung der näheren Umgebung der Stadt, wofür offenbar große Anstrengungen nötig waren. Wohl kaum verblieben den Dänen und ihrem König in einer solchen Lage die notwendigen Ressourcen um irgendwo in Wiek (Läänemaa) in der Peripherie Kirchen zu errichten.

Wann wurde auf Worms dann eine Kirche erbaut - dazu fehlen jegliche schriftlichen Angaben. Selbst die Insel Worms ist erst im Jahr 1391 erstmals in den Quellen erwähnt worden, als Bischof Winrich von Kniprode die Privilegien der Stadt Hapsal bestätigte. ${ }^{12}$

\section{DIE ANLAGE DER KIRCHE AUF WORMS. EINE HOLZKIRCHE}

St. Olai besteht aus Chorraum und Langhaus; ein Turm und eine Sakristei fehlen. Schon ein oberflächlicher Blick von außen zeigt, dass die Kirche nicht nach einem einheitlichen Entwurf fertig gestellt wurde. In den vom Chorraum aus westlich gelegenen

9 August Wilhelm Hupel, Topographische Nachrichten von Lief- und Ehstland, Bd. III (Riga: Hartknoch, 1782), 570.

10 Zum Thema ausführlicher: Ephraim Joel Dahl, „Vormsi ajalugu. Eesti rootsise asustuse ja selle tekkeprobleemide osana“, Vormsi veri IV, hrsg. von Toivo Tomingas (Haapsalu: Haapsalu Trükikoda 2017), 34-35.

11 Kopie des Jahres 1696: Estnisches Historisches Archiv [Eesti Ajalooarhiiv, EAA], 1252-2, 3.

12 Carl Russwurm, Eibofolke oder die Schweden an den Küsten Ehstlands und auf Runö, T1. I (Reval: Kelchen, 1855), 208.

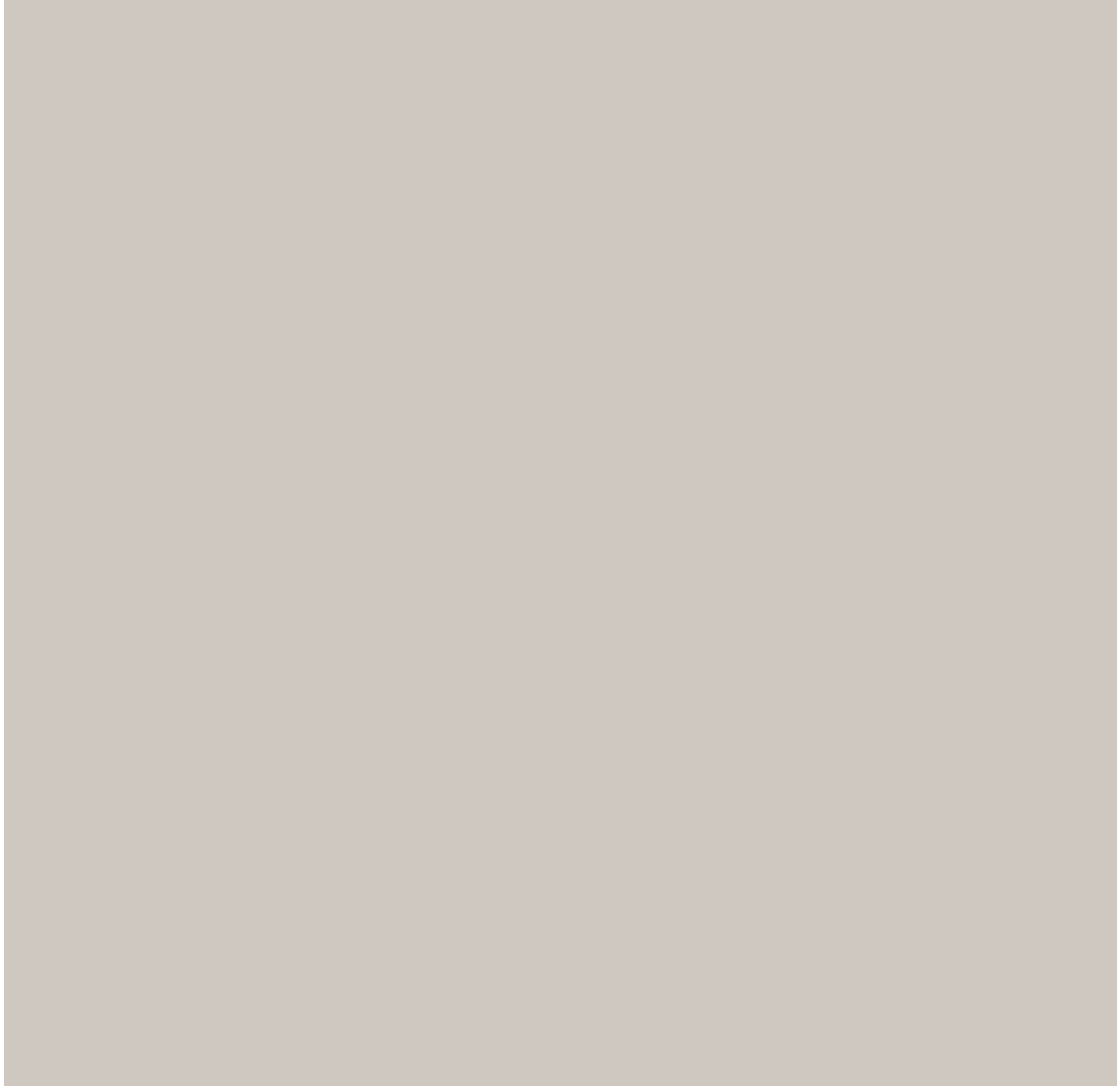

Abb. 2. Grundriss von St. Olai. Zeichnung von Tõnu Parmakson.

Ecken findet sich eine Reihe von aus der Wandoberfläche deutlich emporragenden Feldsteinen. Dies sind Verbindungssteine, welche auf ein geplantes, steinernes Langhaus verweisen. Bis zu dessen Bau kam es aber nicht sobald. ${ }^{13}$ Offensichtlich mussten sich die Bewohner von Worms während des gesamten Mittelalters hindurch mit einem hölzernen, zeitweiligen Gemeinderaum abfinden. Zur Errichtung eines steinernen Langhauses kam es erst im Jahr $1632^{14}$

13 Im Mittelalter wurde gewöhnlich als erstes der Altarraum errichtet und danach wurde damit begonnen, das Langhaus zu bauen. Es passierte auch, dass die Mittel nicht ausreichten und dem Chorraum ein zeitweiliger, hölzerner Gemeinderaum angebaut wurde. Im Bistum Ösel-Wiek wurde so beispielsweise mit den Kirchen auf Moon (Muhu) und in Pyha (Püha) verfahren.

14 Karling, Vormsö kyrka, 10 


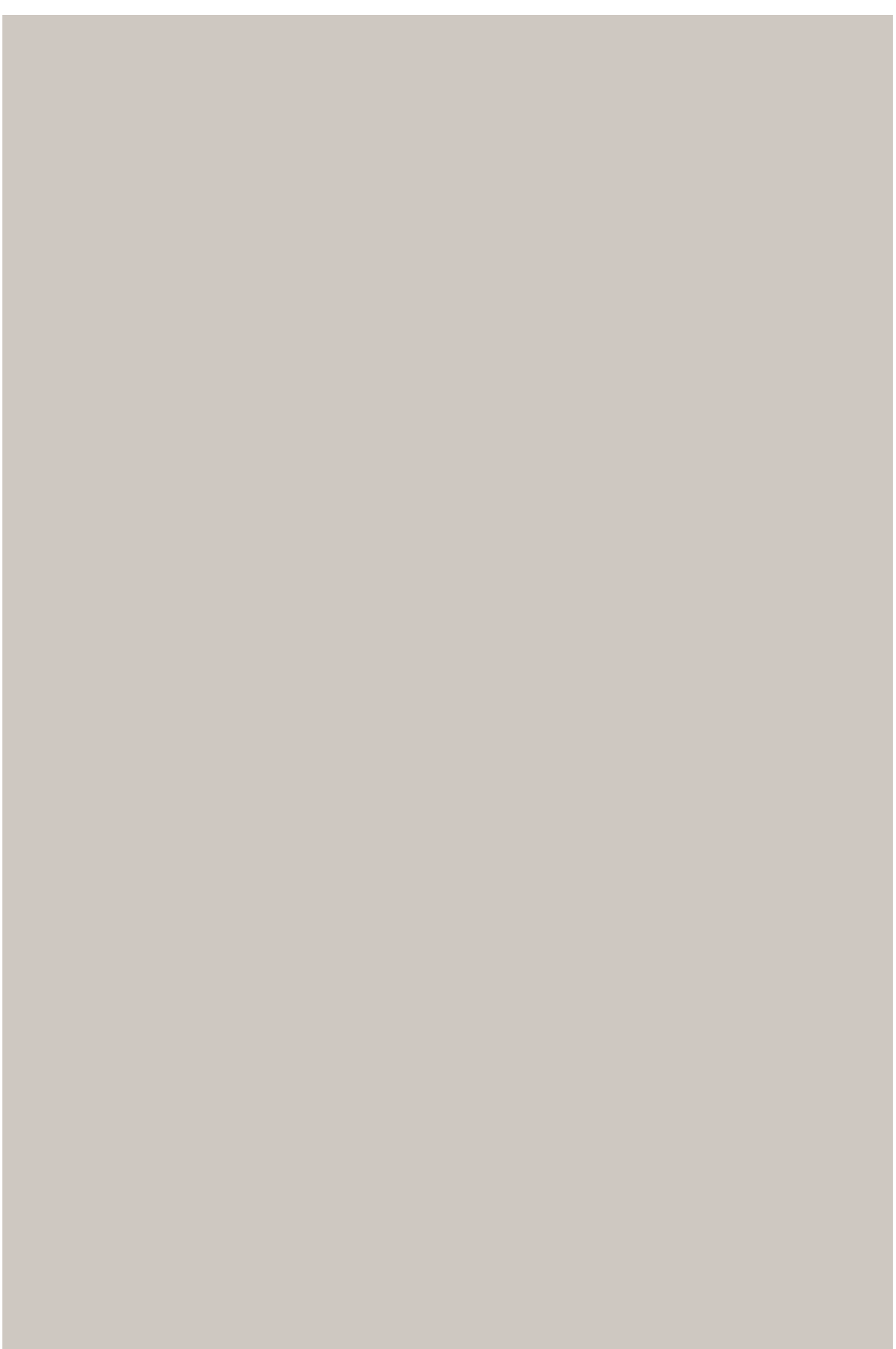

Abb. 3. Verbindungsstelle von Chorraum und Langhaus, Ansicht von Südosten. Beim Bau des Chorraumes wurden im Mauerwerk daraus hervorragende Steine untergebracht, um die Wände des geplanten Langhauses besser anbinden zu können. Rechts das Hagioskop. Foto von Kaur Alttoa.

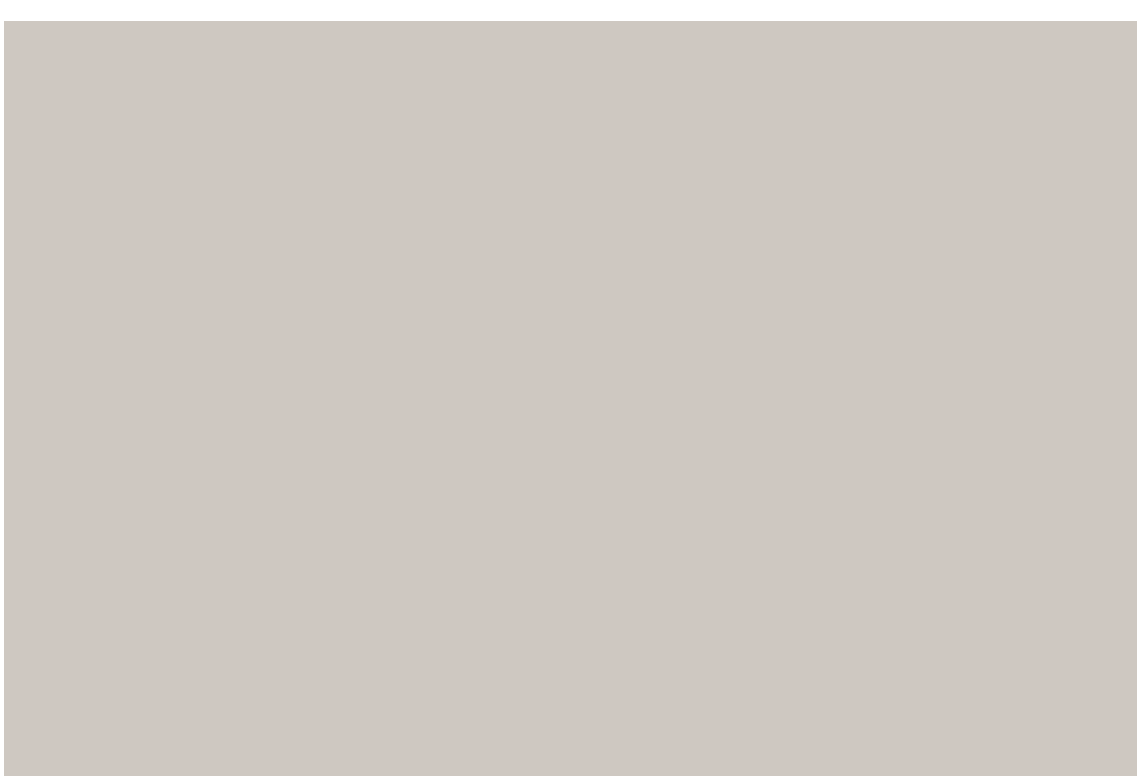

Abb. 4. Interieur von St. Olai. Foto von Kaur Alttoa.

- diese Jahreszahl ist auch auf der westlichen Fassade der Kirche verewigt..$^{15}$ Der kurze und breite Gemeinderaum - die Breite übertrifft die Länge - ist sehr einfach gestaltet: drei Paare schmaler Pfosten aus Holz tragen die horizontale Holzdecke. Die Lösung wiederholt vereinfachend die Gestaltung des um das Jahr 1500 herum erbauten Langhauses der Kirche zu Nuckö, dessen Vorbild offenbar die diele eines mittelalterlichen Kaufmannshauses in Reval war.

Im Verlauf der Wiederaufbauarbeiten von St. Olai ${ }^{16}$ wurden im Bereich des heutigen Langhauses einige wenige Überreste eines von West nach Ost verlaufenden Fundaments aufgefunden, das aus Feldsteinen - ohne Mörtel - gesetzt war. Hierbei handelt es sich um Spuren eines hölzernen Gebäudes, das in etwa über die Breite des heutigen Chorraums verfügte. Es ließe sich nun vermuten, dies wäre ein nach Fertigstellung des Chorraums errichteter, zeitweiliger Gemeinderaum. Diese Vermutung schließt aber ein Detail aus: die 15 Auf der Westfassade befinden sich vier Jahreszahlen: 1219, 1632, 1772 und 1929. Wahrscheinlich
wurde im Jahr 1772 die Kirche repariert und ein massiver Strebepfeiler in der nordöstlichen Ecke des Langhauses errichtet (Raam, Vormsi Olevi kirik“" 42). Die Jahreszahl 1929 markiert den Abschlus der 1925 begonnenen, umfangreichen Renovierungsarbeiten und die erneute Weihung der Kirche.

16 Nach dem 2. Weltkrieg blieb die Kirche ungenutzt und verlassen. Sie wurde in den Jahren 19891990 restauriert (Architekt Tõnu Parmakson). 
Fundamente verlaufen nicht im ganzen Umfang einheitlich und gerade, sondern in ihrem östlichen Teil, vom jetzigen Triumphbogen aus 2,5 Meter westlich, befand sich eine kleine Stufe. Dies bedeutet, dass der östliche Teil des Bauwerks ein wenig schmaler war. Ohne Zweifel verweist dies auf den damaligen Altarraum. Damit liegen hier die Spuren einer Holzkirche vor, die vor dem Bau des heutigen Chorraums errichtet worden war. Die Datierung erlaubende Holzoder Kohlefragmente wurden damals jedoch nicht aufgefunden (oder wusste man nicht, danach zu suchen?), weshalb auch die geringsten Anhaltspunkte für die Festlegung des Alters dieser Holzkirche fehlen. Diese Kirche verfügte auch über einen Westturm aus Holz, die Überreste von dessen etwa $60 \mathrm{~cm}$ dicken Fundament lassen sich vor der westlichen Wand des jetzigen Langhauses betrachten. ${ }^{17}$ Möglicherweise wurde der genannte westliche Teil der Holzkirche auch nach Fertigstellung des Chors als Gemeinderaum genutzt.

\section{DER CHORRAUM VON ST. OLAI}

Nach allgemein verbreitetem Brauch begann der Bau der Kirche auf Worms mit dem Altarraum. In seinem, im Sammelband „Estnische Architektur" erschienenen Beitrag behauptet Villem Raam, dass der Chorraum um das Jahr 1400 fertiggestellt wurde. ${ }^{18}$ Gleichzeitig befindet sich der folgende Text in einem merkwürdigen Gegensatz zu dieser Feststellung: zur Bestätigung der Datierung werden mehrere Parallelbeispiele herangezogen, doch diese stammen alle aus einer späteren Zeit. Tatsächlich hat Raam in einer vorläufigen Fassung eine andere Ansicht bezüglich des Chorraums vertreten: „Wahrscheinlich errichten ihn in der zweiten Hälfte des 15. Jahrhunderts Meister, die entweder aus Padis (Padise) oder Hapsal kamen.."19 Ebenso hat er noch im Jahr 1988 geschrieben: ,„... dieser Chorraum ist von Meistern um die Mitte des 15. Jahrhunderts - entweder im zweiten oder im dritten Viertel - erbaut worden, die bei der Toranlage von Padis ${ }^{20}$ gearbeitet haben.."21

17 Raam, Vormsi kiriku ajalooline õiend, 6.

18 Raam, ,Vormsi Olevi kirik“, 42.

19 Kopie des Manuskripts im Besitz des Verfassers.

20 Raam hat den Torbau des Klosters Padis auf den Zeitraum 1425-1448 datiert (Raam, ,,Arhitektuurija kunstimälestised“, 64-65). Offensichtlich erfolgte die Errichtung der Toranlage dennoch erst nach Fertigstellung und Weihe der Klosterkirche im Jahr 1448.

21 Raam, Vormsi kiriku ajalooline õiend, 9. 


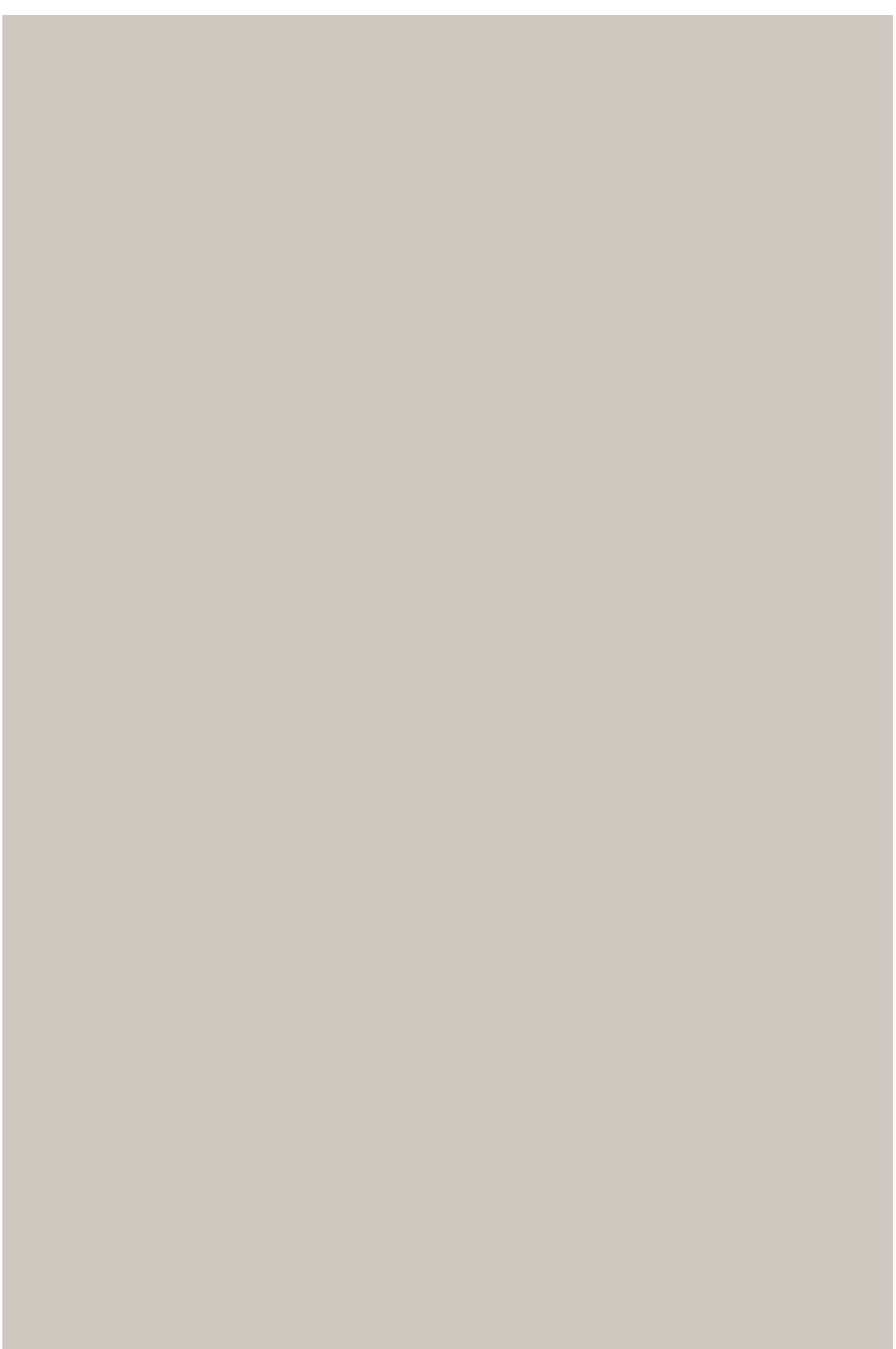

Abb. 6. Konsole der Kapelle der Toranlage von Padis. Foto von Kaur Alttoa.
Für eine solche Veränderung der Datierung gab es einen Grund. Nämlich waren zwischenzeitlich im Verlauf der Restaurierungsarbeiten unter Leitung von Tõnu Parmakson die Gewölbemalereien der Olaikirche entdeckt worden, die laut der Auffassung von Raam nicht auf solch eine späte Zeit zu datieren waren. Deshalb verschob er die Bauzeit der Kirche im Vergleich zu seiner früheren Einschätzung um ein halbes Jahrhundert nach vorne. Irgendwelche Gründe dafür legte er nicht vor. Villem Raams Standpunkt, dass der Chorraum erst im Spätmittelalter erbaut wurde, haben auch spätere Forscher geteilt. ${ }^{22}$

Die angeführte erste Datierung und die Behauptung der in Padis gearbeitet habenden Meister beruhte hauptsächlich auf einem Detail. Nämlich stützt sich das Chorgewölbe in den Ecken auf polygonale pyramidenartige Konsolen. Raam hat darauf verwiesen, dass solch eine Konsolenform auch in der Kapelle des Torturmes des Klosters Padis auftritt. ${ }^{23}$ Genau von diesem Detail leitete er auch die Datierung von St. Olai ab. ${ }^{24}$ Tatsächlich erscheint es als sehr riskant, ein Gebäude auf Basis des Gewölbes zu datieren: gibt es doch sehr viele Fälle, in denen das im Raum verbleibende Gewölbe vorerst nicht gebaut wird - selbst dann, wenn dieses Gewölbe bereits von Anfang an geplant gewesen ist. Auf Grundlage der Gewölbe kann bestenfalls eine Datierung der Wände ante quem abgeleitet werden. Ebenso besteht die Frage, ob eine derartig einfache und logische Konsolenform unbedingt mit bestimmten Vorbildern oder Meistern in Verbindung gebracht werden kann. Eine solche Form vermag ein Steinmetz sich auch unabhängig auszudenken. Die Hauptsache ist aber - bei aufmerksamerer Betrachtung der Konsole in Padis wird deutlich, dass diese doch von irgendwoher stammt und in der Kapelle nur eine sekundäre Verwendung gefunden hat. Unbekannt ist der ursprüngliche Standort der Konsole selbst und ihre Fertigungszeit lässt sich nicht einmal mit der Genauigkeit eines Jahrhunderts feststellen. Damit erscheint es als klar - die Gewölbekonsole des Chors von St. Olai bietet momentan keinerlei Hilfe bei der Aufklärung der Baugeschichte

22 Kersti Markus, „From Rus 'Trade to Crusade: St. Olaf’s Churches in the Eastern Baltic Sea Region“, Acta Historica Tallinnensia, 23 (2017) (im Erscheinen).

23 Raam, Vormsi kiriku ajalooline õiend, 8.

24 Eine ähnliche Konsole war die einzige Grundlage der Datierung der Kirche zu Fickel (Vigala) in Süden Osel-Wieks auf das vierte Viertel des 15. Jahrhunderts (Villem Raam, „Vigala Maarja kirik“, Eest Arhitektuur 3. Harjumaa, Jarvamaa, Raplamaa, Läane-Virumaa, Ida-Virumaa (Tallinn: Valgus, 1997), 116. Bei der Analyse des Grundrisses der Kirche zu Fickel kam Kersti Markus zu der Schlussfolgerung, dass die Mauern des Gebaudes eher aus dem 13. Jahrhundert stammen. Auf Raams Datierung der des 15. Jahrhunderts kam (Kersti Markus, Raplamaa kirikud (Tallinn: Muinsuskaitseamet, 2002), 45). 
der Kirche und es gilt, sich auf andere besondere Züge des Gebäudes zu konzentrieren.

Das Interieur des Chorraums von St. Olai ist in einer sehr besonderen und eigenen Weise gestaltet. Die östliche Wand verläuft nicht gerade, sondern in ihr befindet sich eine offene spitzbogige Nische. Ebenso ist auch die südliche Wand des Altarraums gestaltet. ${ }^{25}$ Etwas unterschiedlich ist die nördliche Wand. Deren unterer Teil ist bis zu den Gewölbekonsolen massiv. Die Gestaltung der oberen Zone wiederholt die Komposition der Ost- und der Südseite, im unteren Teil befinden sich aber drei Nischen mit einem dreieckigen Sturz. Ihre Funktion ist unbekannt. Villem Raam hat als eine Möglichkeit angeboten, dass die mittlere Nische mit einem Nebenaltar verbunden gewesen war, die kleinen sollten aber der Aufbewahrung des Zubehörs für die Sakramentengeräte dienen, denn der Kirche fehlte die Sakristei. ${ }^{26}$

Am aussagereichsten ist die östliche Wand mit Nische des Chorraums von St. Olai. Mit anderen Worten ist der Altarraum um eine Stufe schmaler als der Ostteil, der über ein eigenes Gewölbe verfügt. Als solche wurde in einer Miniaturform eine Komposition genutzt, die in den Klosterkirchen der Zisterzienser weit verbreitet ist - am bekanntesten ist wohl Fontenay in Burgund. Ein an Estland am dichtesten gelegenes Beispiel findet sich im Kloster Alvastra in Schweden. ${ }^{27}$ Den entsprechenden Typ des Chors hat in Estland Villem Raam wohl behandelt ${ }^{28}$, doch St. Olai wird in diesem Zusammenhang von ihm gar nicht erwähnt.

25 Auf eine ganz andere Weise hat Raam diese Wandgestaltung interpretiert. Laut ihm verfügt der Chorraum über auffallend dünne, $92-95 \mathrm{~cm}$ starke Wände. Um ein Gewölbe zu errichten, wurden in den inneren Ecken der Mauerwand innere Strebepfeller erbaut, die unterenander mit Bogen verbunden waren. Als analoge Lösungen benennt der Forscher die Kirchen zu St. Michaelis (Mihkli), Kegel (Keila) und Jewe (Jõhvi) (Raam, Vormsi kiriku ajalooline õiend, 7). Doch handelt es sich - ungeachtet de äußeren Ähnlichkeit - um verschiedene Lösungen. Die genannten Kirchen wurden anfangs mit dünnen Wanden und ondeiler

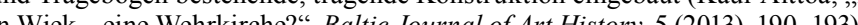

26 Raam, Vormsi kiriku ajalooline õiend, 9-10.

27 Bei der Untersuchung von Chorräumen in Zentral- und Westestland ist auf Alvastra bereits vorher hingewiesen wurden (Villem Raam, ,,Nelinurkse kooritüübi mõningatest variatsioonidest Eesti keskaegses . Doctissimo et Expertissimo, hrsg. von Kaur Alttoa (Tallinn: Eesti Muinsuskaitse Selts, 1995), 46-47). Wie aber gelangte die Lösung für den Ostteil der Altarräume von Hapsal und von Worms nach AltLivland und spielte hierbei das Kloster Alvastra eine Rolle - diese Themen überschreiten den Rahmen dieses Beitrags.

28 Raam, „Nelinurkse kooritüübi mõningatest variatsioonidest Eesti keskaegses arhitektuuris“, 88-117. 


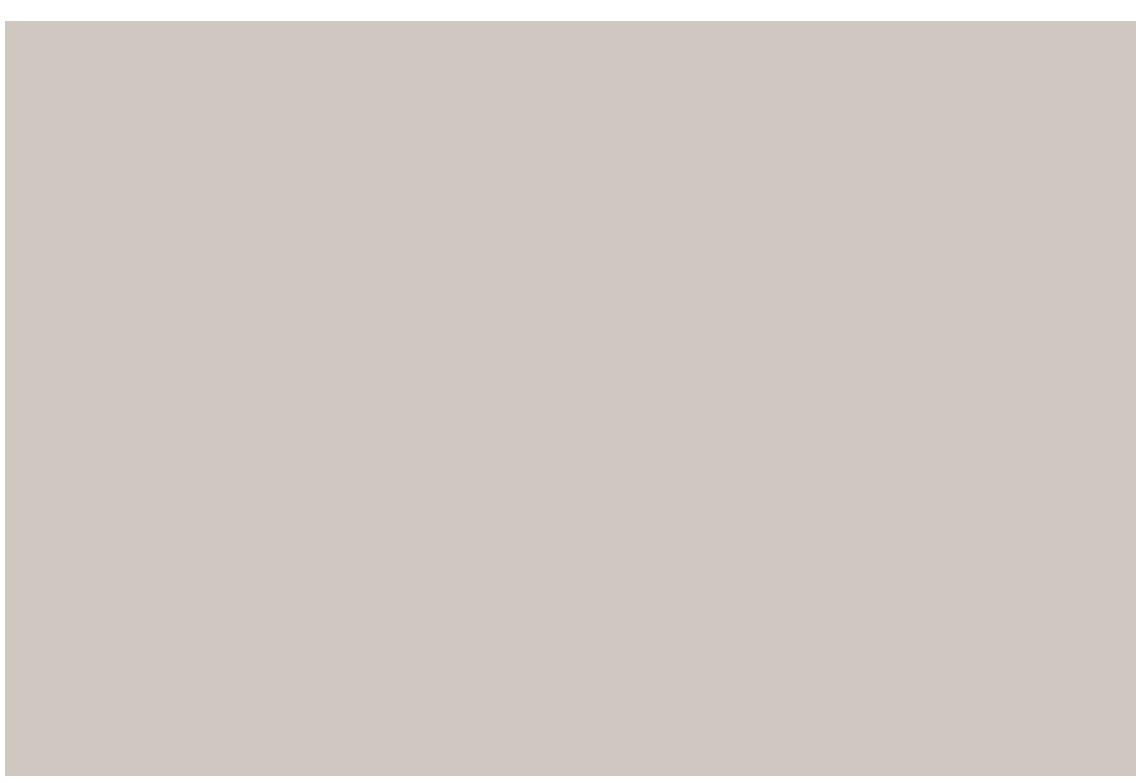

Abb. 8. Kapitell der Domkirche zu Hapsal. Foto von Kaur Alttoa.

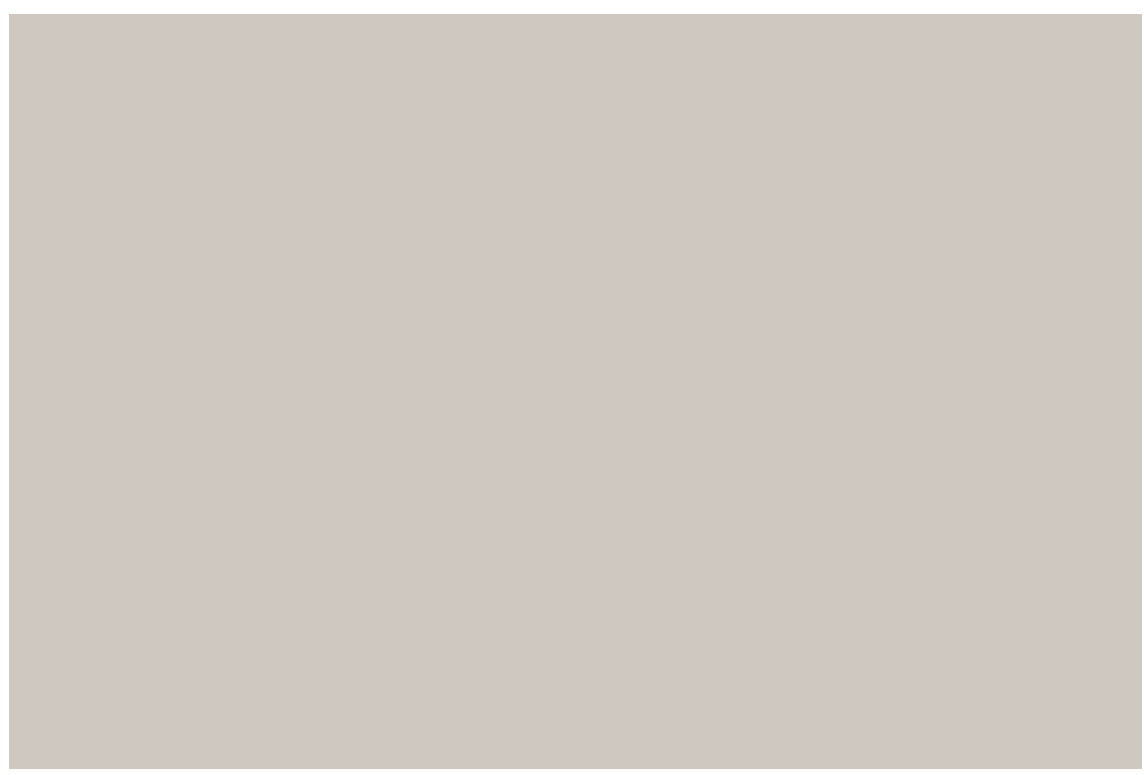

Abb. 9. Kapitell des Kapitelsaals der Domkirche zu Riga. Foto von Kaur Alttoa.

\section{DIE DOMKIRCHE ZU HAPSAL}

Ähnlich wie in St. Olai ist die östliche Wand der Domkirche des Bistums Ösel-Wiek in Hapsal gestaltet, so dass es als offensichtlich erscheint, dass diese als eine Art Vorbild für die Kirche auf Worms diente. Also erscheint es zur Lösung der Probleme von St. Olai erstmal als notwendig zu wissen, wann die Hauptkirche des Bistums fertiggestellt wurde.

Die Domkirche zu Hapsal stellt eine komplette Ausnahme unter den Kathedralen Alt-Livlands dar. Dabei handelt es sich um einen ungewöhnlich einfachen, einschiffigen, dreijochigen Bau ohne selbständigen Chorraum, der den Südflügel der Bischofsburg umfasst. In der Kirche befinden sich reich verzierte Kapitelle der Wandpfeiler, bei denen sowohl romanische als auch frühgotische Motive verwendet wurden. Am wichtigsten ist das westlichste Kapitell der nördlichen Wand der Kirche. Es handelt sich um ein Knospenkapitell. Das bemerkenswerteste Detail ist aber ein von einem Palmettenornament inspiriertes Blattpaar auf dem Vordergrund des Kapitells, das - mit den Worten Villem Raams - „wie zu einer gegenseitigen Verneigung gegeneinander zugeneigt ist ${ }^{\prime 2}{ }^{29}$ Stilistisch gehört das Kapitell zum Grenzland zwischen zwei Zeitaltern: neben den der Frühgotik eigenen Knospen findet sich an den Blattstielen eine Leiste mit romanischen Diamantquadern. Genau dieselben Motive und auch dieselbe Handschrift liegen in Alt-Livland noch zweimal vor. Dies sind die Kapitelle im Kapitelsaal der Domkirche zu Riga und die Zwickelkolonette der Kirche zu Karmel (Kaarma) auf der Insel Ösel (Saaremaa). Auf Grundlage einer solch großen Ähnlichkeit kann mit erheblicher Sicherheit behauptet werden: sie alle wurden von einem Meister geschaffen. ${ }^{30}$ Tatsächlich war wenigstens ein Mann, der die Bauskulptur von Hapsal schuf, von der Bauhütte der Domkirche zu Riga gekommen. Anschließend führte ihn sein Weg weiter nach Ösel. Also muss nach heutigem Forschungsstand bei der Datierung der Domkirche zu Hapsal vor allem von der Bauplastik der Rigaer Domkirche ausgegangen werden. Agnese Bergholde hat das Dekor des Kapitelsaals der Domkirche zu Riga in die Jahre 1240-1260

29 Villem Raam, „Ridala Maarja-Magdaleena kirik“, Ars Estoniae medii aevi. Grates Villem Raam Viro Doctissimo et Expertissimo, hrsg. von Kaur Alttoa (Tallinn: Eesti Muinsuskaitse Selts, 1995), 13. 30 Kaur Alttoa, ,Mõningaid Valjala ja Kaarma kiriku ehitusloo probleeme“, Saaremaa Muuseum kaheaastaraamat 2001-2002 (Kuressaare, 2003), 6-8; Kaur Alttoa, ,Haapsalu linnuse kujunemisloos märkmeid ja märkusi“", Läänemaa Munseumi toimetised XVII (Haapsalu, 2014), 45-47. 
eingeordnet. ${ }^{31}$ Offenbar wurde auch der Hauptteil der Domkirche zu Hapsal in den sechziger Jahren des 13. Jahrhunderts gebaut. ${ }^{32}$

\section{DIE HERKUNFT DER ÖSTLICHEN NISCHEN IN HAPSAL UND AUF WORMS ${ }^{33}$}

Also hatte wenigstens einer der Meister der Kapitelle der Hapsaler Domkirche zuvor in Riga gearbeitet. Natürlich tritt sofort die Frage auf, ob nicht auch die Anlage und die architektonische Komposition der Domkirche von Hapsal von dort - aus Riga und Umgebung stammt? War doch Riga wenigstens im ersten halben Jahrhundert nach der Eroberung des Baltikums wichtigstes Vorbild für die hiesigen architektonischen Formen und ihr bedeutendster Vermittler. Das zu Dänemark gehörige Nordestland stellte natürlich ein eigenes Thema

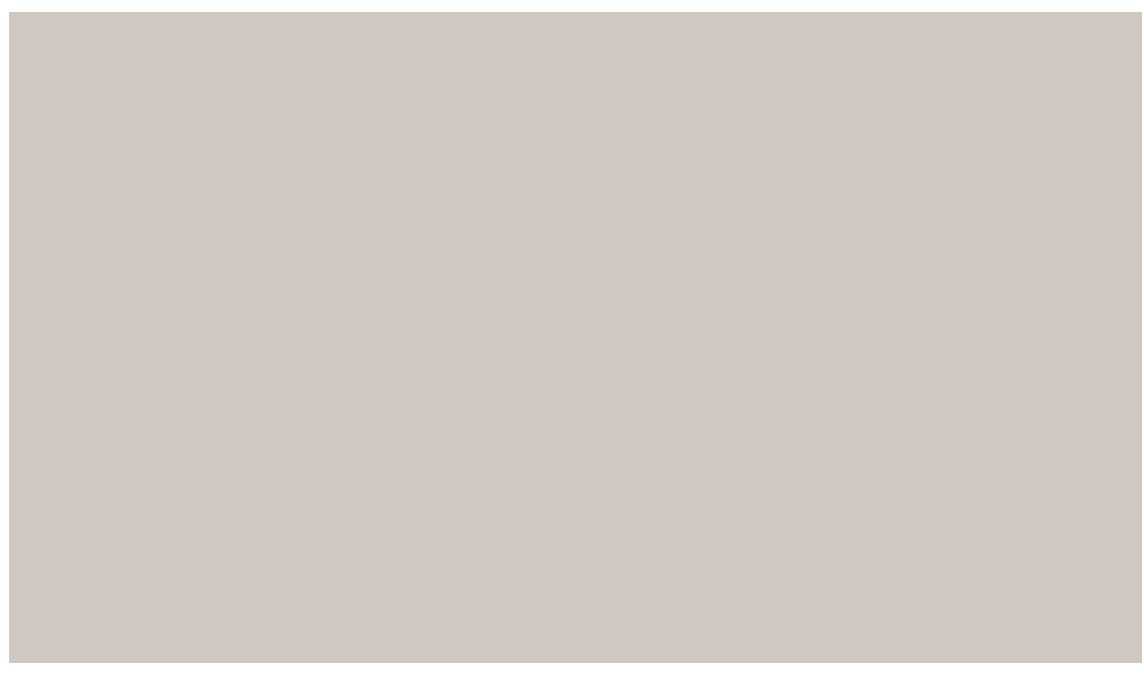

Abb. 10. Grundriss der Kirche zu Holme. Ieva Ose, „Einige Erkenntnisse über die ersten Kirchen in Lettland“, Kirche und Kunst im Ostseeraum (Toruń, 1998).

31 Agnese Bergholde, Rìgas Doma viduslaiku arhitektūra un būvplastika eiropeisko analoǵiju kontekstä (Riga: Latvijas Măkslas akadēmijas Mākslas vêstures institūts, Măkslas vêstures pêtijum atbalsta fonds, 2015), 329.

32 Alttoa, „Haapsalu linnuse kujunemisloost: märkmeid ja märkusi“, 47-49. Diese Kirche war vorers offensichtlich ohne Gewölbe gebaut worden, doch dieses war bereits anfangs geplant gewesen.

33 Zum selben Thema: Alttoa, „Mõningaid Valjala ja Kaarma kiriku ehitusloo probleeme“, 22-25, Alttoa, ,Kui piiskop polnud veel Haapsallu jõudnud“, Läänemaa Muиseumi toimetised XVI (Haapsalu, 2013), 20-22.

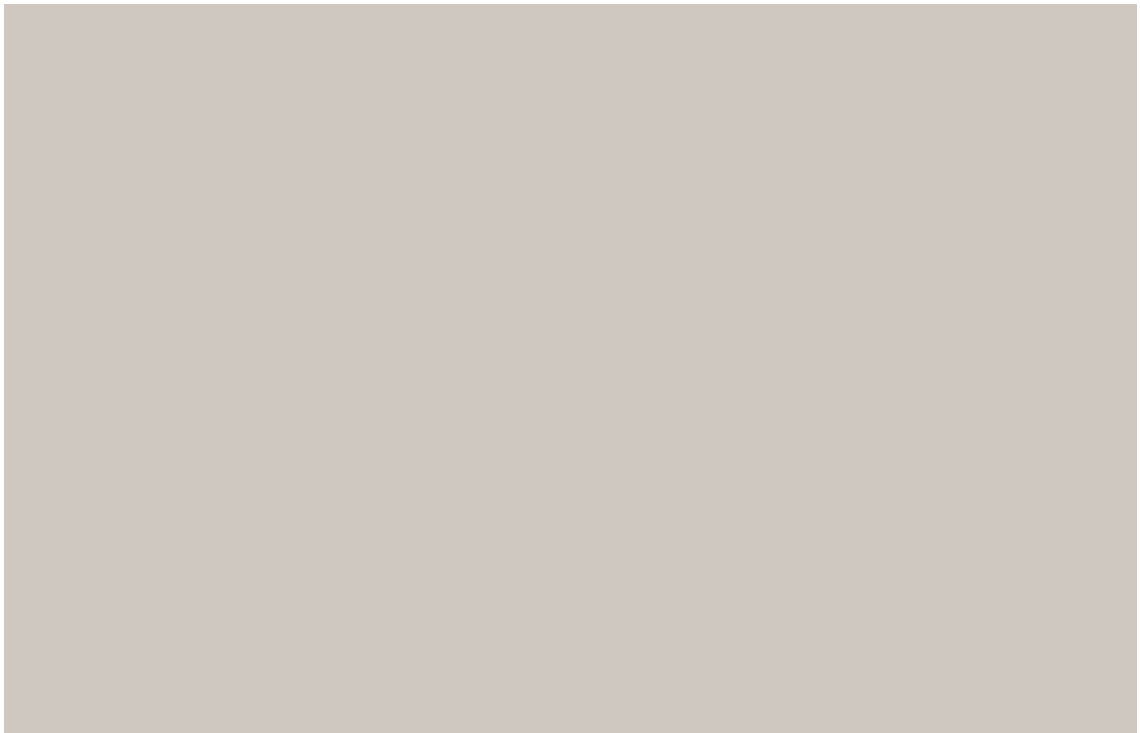

Abb. 11. Südöstlicher Teil der Kirche zu Holme. Links die Reste der östlichen Nische. Foto von Kaur Alttoa (1972).

dar. In Riga wurde bereits früh ein dreischiffiges Kirchengebäude dominierend. Wohl bestand auch hier in der Region eine bemerkenswerte Ausnahme - die Kirche zu Holme (Mārtinsala) in Lettland. ${ }^{34}$ Es handelte sich um eine etwa aus der Mitte des 13. Jahrhunderts stammende, ${ }^{35}$ einschiffige, dreijochige Kirche ohne einen eigenständigen Altarraum. Damit liegt eine vollkommene Entsprechung der Domkirche zu Hapsal vor, die nur kleiner war (innere Breite entsprechend 11,5 $\mathrm{m}$ und 8,5 m). ${ }^{36}$

34 Nach dem Bau des Düna-(Daugava-)Staudamms bei Kirchholm (Salaspils) versank die gesamte Insel Holm zusammen mit den Ruinen der Kirche und der Ortschaft unter die Wasseroberfläche.

35 Die Datierung stützt sich auf die im Verlauf von 1968-1974 erfolgten archäologischen Ausgrabungen unter der südlichen Wand der Kirche aufgefundenen Grabstätten, die aus der ersten Hälfte des 13 . Jahrhunderts stammen müssten (leva Ose, „Einige Erkenntnisse über die ersten Kirchen in Lettland“ Kirche und Kunst im Ostseeraum. Studia Borussico-Baltia Toruniensia Historiae Artium, 3 (Toruń, 1998), 63).

36 Auf den ersten Blick besteht hier auch ein wichtiger Unterschied, im Gegensatz zu Hapsal sind die Wände des westlichen Gewölbes der Kirche zu Holme bedeutend massiver. Auf dieser Basis ist behaupte worden, dass das Turmgewölbe erst in einem zweiten Bauabschnitt, wahrscheinlich im 14. oder 15 Jahrhundert, hinzugefügt wurde (Andris Caune, Ieva Ose, Latvijas viduslaiku müra baznīcas 12. gs. beigas - 16. gs. sākums. Enciklopēdija (Riga: Latvijas vēstures institūta apgāds, 2010), 386, 390-391). Tatsächlich war die Außenseite des Mauerwerks der Längswände der Kirche zu Holme homogen, ohne irgendwelche Anzeichen für Veränderungen oder Umbauten. Im Interieur dagegen waren im westlichen

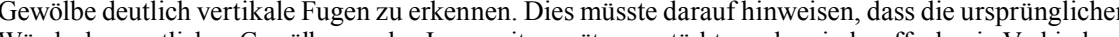
Wände des westlichen Gewölbes an den Innenseiten später verstärkt worden sind - offenbar in Verbindung mit dem Wunsch einen Turm zu erbauen. 


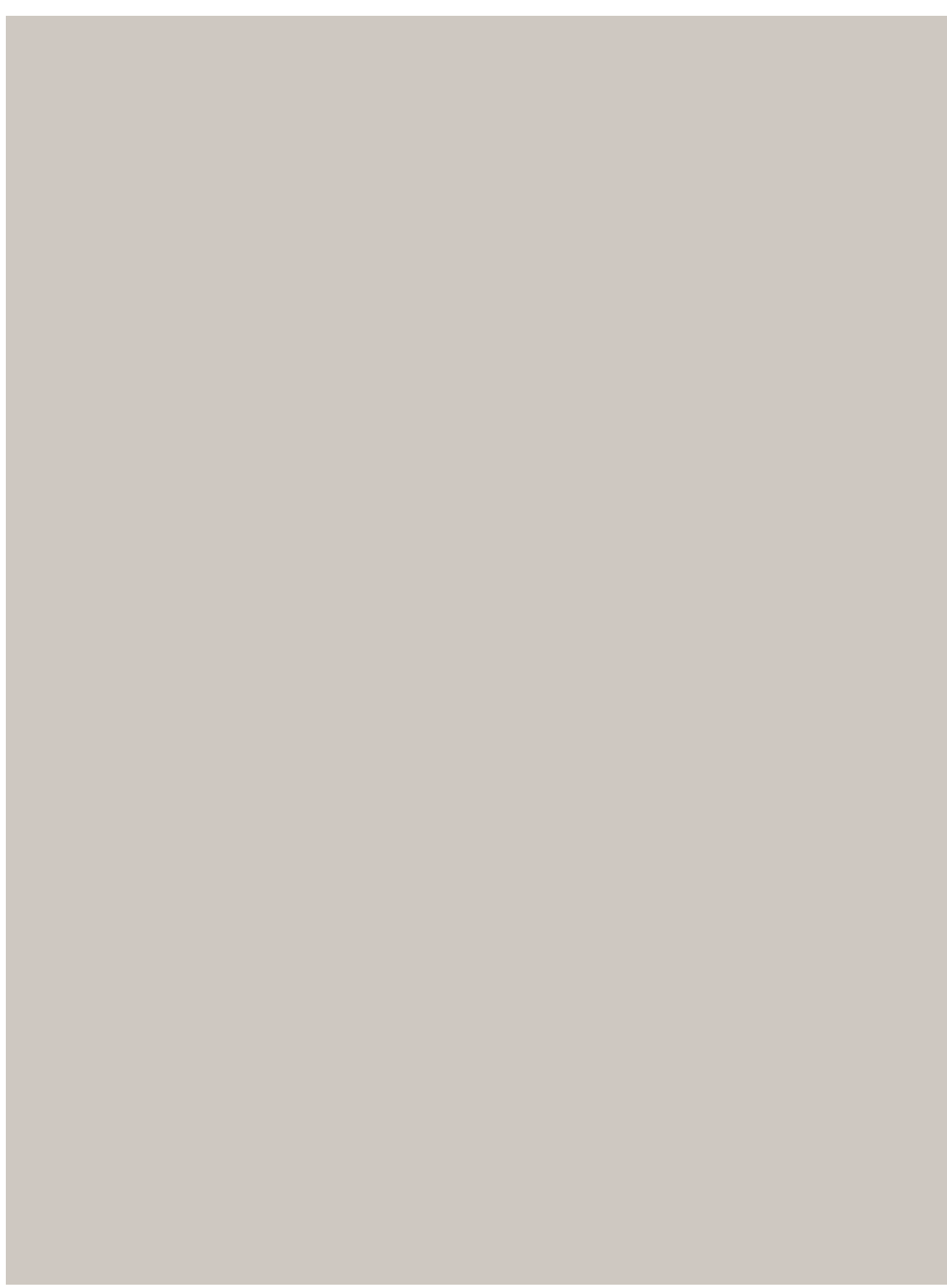

Abb. 12. Die östliche Wand des Chorraums der Nikolaikirche in Pernau. Foto von Johannes und Peeter Parikas.

Was aber die Hauptsache ist - auch die östliche Wand der Kirche zu Holme wurde durch eine, nahezu die gesamte Wandzone umfassende spitzbogige, breite Nische gegliedert. Deren Bogenteil war bereits bis zum Anfang des 20. Jahrhunderts zerstört, wohl aber waren seine Leibungen erhalten geblieben. Also liegt eine vollkommene Entsprechung der Domkirche zu Hapsal vor und augenscheinlich waren die Gebäude untereinander genetisch verbunden. Eine eigene Frage besteht darin, ob die Domkirche zu Hapsal unmittelbar die Anlage der Kirche zu Holme kopierte oder bestand für sie beide ein gemeinsames, inzwischen zerstörtes Vorbild.

Auf der Strecke Riga-Hapsal liegt noch Pernau (Pärnu). Tatsächlich befanden sich hier im Mittelalter zwei Städte. Am rechten Ufer des Flusses lag Alt-Pernau, das vor Hapsal für eine kurze Zeit Zentrum des Bistums Ösel-Wiek war. Das linke Ufer des Flusses gehörte aber zum Territorium des Livländischen Ordens und hier erstreckte sich die Stadt Neu-Pernau (Uus-Pärnu), der die Parochialkirche St. Nikolaus geweiht war. ${ }^{37}$

Über die um das Jahr 1251 fertiggestellte und von den Litauern 1263 zerstörte Domkirche zu Alt-Pernau ${ }^{38}$ sind ausgesprochen wenig Angaben überliefert. Sicher ist aber eins - auch hier gab es den bereits bekannten, einschiffigen und dreijochigen Lageplan. Informationen über die Gestaltung der Ostwand der Domkirche fehlen. Der Chor der Nikolaikirche zu Neu-Pärnu verfügte aber über eine ähnliche östliche Nische wie die Hapsaler Kirche. Es ist nicht unmöglich, dass dieses Motiv von der auf der anderen Seite des Flusses gelegenen Domkirche oder ihren Ruinen entlehnt wurde. Es verdient auch noch unsere Aufmerksamkeit, dass die Längswände des Chorraums der Nikolaikirche denen von St. Olai auf Worms ähnelten - eingeschlossen der eigentümlichen Gestaltung der nördlichen Wand. Damit besteht kein Zweifel, dass zwischen diesen beiden Chorräumen ein architektonischer Zusammenhang besteht. Leider ist es heutzutage nicht mehr möglich zu sagen, welcher von beiden älter war

\section{VERSUCH DER DATIERUNG}

\section{DES CHORRAUMS VON ST. OLAI}

Im Bistum Ösel-Wiek erfolgte im 13. Jahrhundert ein überraschend intensiver Bau von Parochialkirchen. Auf Ösel gab es wenigstens fünf

37 Zur Pernauer Nikolaikirche, die im Zweiten Weltkrieg brannte und anschließend gesprengt wurde: Kaur Alttoa, ,Die Kirche zu Urbs / Urvaste und die Frage der Rigenser Bauschule im 13. Jahrhundert", Baltic Journal of Art History, 6 (2013), 19-27.

38 Siehe: Alttoa, ,Kui piiskop polnud veel Haapsallu jõudnud“, 16-32. 
von ihnen ${ }^{39}$, auf dem Festland des Bistums aber neun. ${ }^{40}$ Zusammen genommen sind bis heute elf erhalten geblieben. Wohl verfügt keine von ihnen über eine ähnliche östliche Wand des Altarraums wie in Hapsal oder auf Worms. Auf dieser Grundlage mag vermutet werden, dass der Chorraum von St. Olai dann erbaut wurde, als eine solche Komposition ein wirklich aktuelles Thema war - bald nach der Fertigstellung der Domkirche zu Hapsal. Damit könnte die Errichtung des Chorraumes der Kirche auf Worms nicht später als in die siebziger Jahre des 13. Jahrhunderts gefallen sein. ${ }^{41}$ Ausgeschlossen ist auch nicht das vorhergehende Jahrzehnt. In den achtziger Jahren des 13 Jahrhunderts wäre diese Lösung aber im Bistum Ösel-Wiek bereits hoffnungslos altmodisch gewesen. Es sollte noch einmal betont werden, es geht um das Mauerwerk des Chorraums, nicht um das Gewölbe. Es ist nicht ausgeschlossen, dass es erst bedeutend später zum Bau des Gewölbes kam.

\section{GEWÖLBEMALEREI}

Ein eigenes Thema ist das Gratgewölbe des Chorraums der Olaikirche. Für dessen Errichtung wurden sowohl Kalkstein als auch Backsteine verwendet. Aus den letzteren sind auch die Ränder der Kappe im unteren Bereich des Gewölbes gemauert, wo die kleinen Furchen als Rillen gestaltet sind. Villem Raam hat als Parallelbeispiele für diese Lösung die Kirche zu Fickel, die Vasallenburg in Türpsal (Järve) und den Kirchturm von Röthel (Ridala) angeführt. ${ }^{42}$ Möglicherweise helfen in der Zukunft die Malereien, die im Verlauf des letzten Wiederaufbaus beim Säubern ans Tageslicht kamen, die Baugeschichte des Chorraums von St.

39 Bis heute sind die Kirchen zu Wolde (Valjala), Karmel (Kaarma), Karris (Karja) und Kielkond (Kihelkonna) erhalten geblieben. Dazu zählte auch die im Jahr 1842 abgerissene Kirche von Kerge begonnen worden war, d

40 Zusätzlich zu Worms sind zu nennen Pönal (Laäne-Nigula), Röthel (Ridala), Hanehl (Hanila), St. Michaelis (Mihkli), Fickel (Vigala), Goldenbeck (Kullamaa) und Leal (Lihula; abgerissen in den siebziger Jahren des 19. Jahrhunderts). Doch die Aufzählung endet noch nicht, zu erwähnen ist die Kirche von St Martens (Martna), die 1299 vom Livlandischen Orden zerstort wurde (Juhan Kilumets, ,Martna püh Martini kirik ", Martna kihelkond. Artikleid ja mälestusi. 700 aastat Martna esmamainimisest (Martna 998), 3-4). Die heutige Form der Kirche zu St. Martens stammt vom Beginn des 16. Jahrhunderts.

41 Erstmals ist der Chorraum von St. Olai auf das 13. Jahrhundert datiert worden: Kaur Alttoa, 101 pühakoda (Tallinn: Varrak, 2015), 116.

42 Raam, „Vormsi Olevi kirik“, 42 


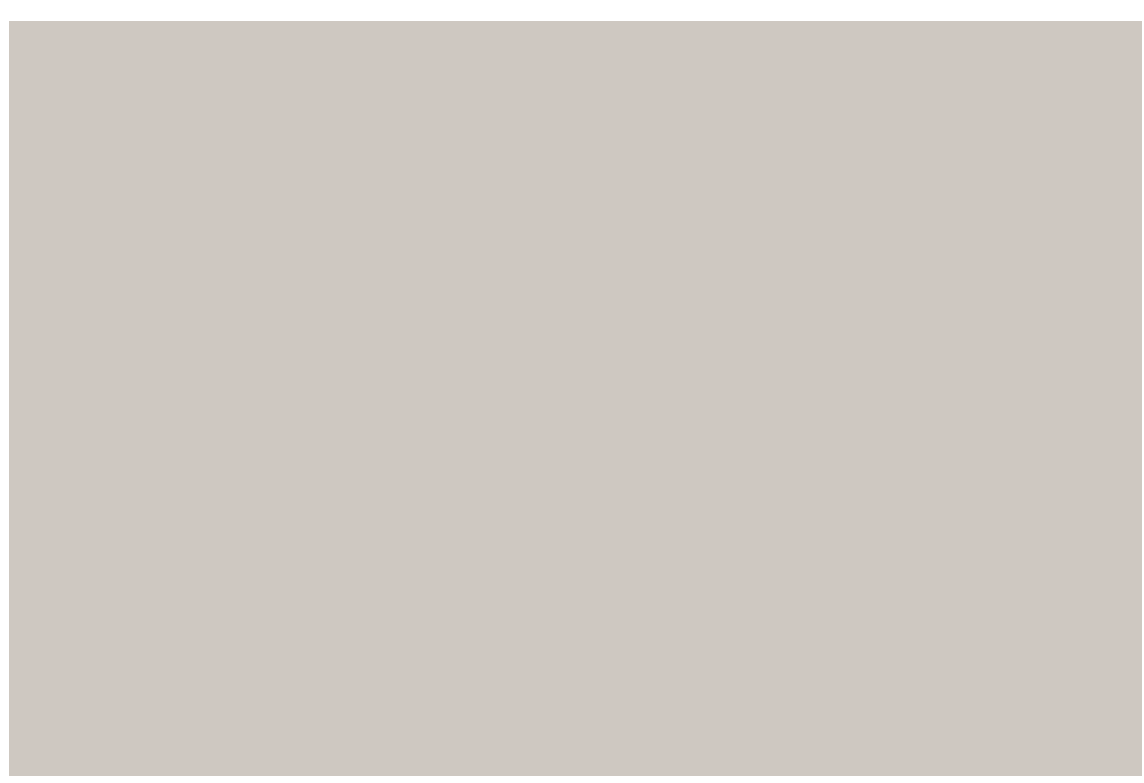

Abb. 14. Salvator mundi im Chorgewölbe der Kirche zu Röthel. Foto von Kaur Alttoa.

Olai zu präzisieren. In Estland sind sie einzigartig. Doch der Verfasser kennt sich auf diesem Gebiet nicht aus. Aber Villem Raams vorläufige Einschätzung über sie verdient es, weiter gegeben zu werden: „Den Kompositionsrhythmus geben die in Form von Wulstrippen kolorierten Gewölbegrate vor: vier Bänder, die beim aufgemalten Schlussring anfangen. Nur zur halben Gewölbedecke reichend, bilden sie zusammen mit den Blütenmotiven einen großen Baldachinkranz. Dreiblättrige, glockenblumenähnliche Lotosblumen, Sternmotive und einzelne große Lilienblüten symbolisieren den paradiesischen Lebensbaum. Wahrscheinlich wurde versucht, auf den Altarraum als Symbol des Paradieses zu verweisen. Die Vorbilder dieser Gestaltung stammen offensichtlich aus Gotland, doch auch Westfalen ist nicht ausgeschlossen.."43

Gotlands barockartig reich bemalte "Paradiesgewölbe“ stammen aus dem 13. Jahrhundert - die spätesten von ihnen dürften um das Jahr 1300 entstanden sein..$^{44}$ Die Malereien auf Worms sind

43 Villem Raam an Kaur Alttoa, 1990 (?). Notizen im Besitz des Verfassers.

44 Bengt G. Söderberg, Gotländsks kalkmålningar 1200-1400 (Uppsala: Föreningen Gotlands Fornvänner Visby, 1971), 83-90. Das erwähnte Werk bildete zweifelsohne Villem Raams hauptsächliche Informationsquelle. 
ausgeprägt einfach und augenscheinlich primitiv. Offenbar zählte ihr Urheber nicht zu den professionellen Meistern. Als Parallele sollte auf Schweden verwiesen werden, wo im Spätmittelalter eine ziemlich primitive Malweise anzutreffen ist, die in manch einem Fall als naiv zu bezeichnen wäre. ${ }^{45}$ Auch in Estland ist dieser Stil nicht unbekannt. Dazu zählt wahrscheinlich der aus dem 15 Jahrhundert stammende und im Schlussring des Chorraums in Röthel befindliche Salvator mundi. ${ }^{46}$ Grundsätzlich eine ähnliche Manier (aber nicht die Formenwelt!) vertritt auch ein im Jahr 2016 freigelegte Malereifragment an der Spitze des westlichen Gewölbes der Kirche zu Peude (Pöide). Hier sind auf den Graten des Gewölbes rote Bänder gemalt, die mit Lilienmotiven abschließen. Handelt es sich auch hier eventuell um einen sogenannten Baldachinkranz, auf den Raam im Fall von Worms verwies? An der Spitze des Gewölbes ist aber ein Männerkopf aufgemalt. ${ }^{47}$ In all jenen Fällen besteht der gemeinsame Nenner darin, dass für die Dekorierung der Kirche kein professioneller Künstler angeworben wurde, sondern die Arbeit wurde einem, deutlich nicht besonders talentiertem Liebhaber anvertraut. Zur selben Zeit sind alle drei Beispiele sehr unterschiedlich und in keinem Fall besteht bezüglich von ihnen Anlass, die Folgerung von ein und demselben Meister zu treffen.

\section{HAGIOSKOP UND SAKRAMENTSNISCHE}

Im Chorraum St. Olais finden sich noch zwei besondere Details. In der südlichen Wand etwa in Gesichtshöhe liegt ein Fensterchen mit Steinrahmen mit einer sich einem Quadrat annähernden Form. Es handelt sich um eine Gucköffnung oder ein Hagioskop. In Estland findet sich ein Hagioskop noch in der Kirche zu Hanehl (Wiek) und in der westlichen Wand des Klosters in St. Brigitten (Pirita klooster).

45 Für entsprechende Illustrationen siehe beispielsweise: Åke Nisbeth, Bildernas predikan Medeltida kalkmålningar i Sverige (Gidlund: Kungl. Vitterhets Historie och Antikvitets Akademien, Riksantikvarieämbetet, 1986), 129-200; Anna Nisén, Programm och funktion i senmedeltida kalkmåler Kyrkmålningar i Malarlandskapen och Finnland 1400-1534 (Stockholm: Kungl. Vitterhets Historie oc Antikvitets Akademien, 1986)

46 Mai Lumiste, „,Maal, puuskulptuur ja tarbekunst 13. sajandist kuni 16. sajandi teise veerandini“ Eesti kunsti ajalugu kahes köites, I (Tallinn: Kunst, 1975), 71-82.

47 Hilkka Hiiop, Juhan Kilumets, Anneli Randla, ,Kes vaatab vastu Pöide võlvilt?“', Järelevastamine. Kaur Alttoale. Eesti Kunstiakadeemia toimetised, 22 (Tallinn, 2017), 273-284
Das letzter eröffnete den Blick auf den Altar der Heiligen Birgitta (von Schweden). ${ }^{48}$ Nach Estland gelangte das Thema des Hagioskops durch einen Aufsatz von Armin Tuulse. ${ }^{49}$ Laut der traditionellen Auffassung waren derartige Fensterchen für solche Menschen gedacht, die aus irgendeinem Grund die Kirche nicht betreten durften - Leprakranke, Büßer und Exkommunizierte. So konnten sie an der Heiligkeit und den Riten der Kirche teilnehmen. Jedoch spielten bei der Herausbildung dieser Hypothese auch die Legenden des Zeitalters der Romantik eine Rolle und mit Leprakranken haben diese Öffnungen in Wirklichkeit wenig zu tun. ${ }^{50}$ Offensichtlich waren sie vor allem ein Vermittler eigener Art zwischen dem Kirchenraum und der Außenwelt: durch sie hindurch konnte die Heiligkeit der Kirche erfahren werden, unabhängig davon, ob die Türen der Kirchen gerade geschlossen waren oder ob im Moment eine Missa erfolgte. ${ }^{51}$

Weiterhin befindet sich im nördlichen Teil der östlichen Wand des Chorraums von St. Olai eine besondere Sakramentsnische. An ihrer Rückseite liegt ein Schacht, der sich zur äußeren Oberfläche der Mauer öffnet. Auf Grundlage der Bauspuren erscheint es als klar, dass dieser nicht aus der Bauzeit des Chorraums stammt, sondern später durchgebrochen wurde. Solch eine Komposition einer Sakramentsnische ist außerordentlich selten. Auf jeden Fall habe ich eine solche Nische nirgendwo im Abendland angetroffen

48 Villem Raam, Pirita klooster (Tallinn: Eesti Raamat, 1984), 22

49 Armin Tuulse, „Bönekamar och hagioskoop“, Konsthistoriska studier tillägnade Sten Karling (Stockholm: Konsthistoriska Institutionen Kungliga Universitetet, 1966), 11-24. Siehe auch: Kunstileksikon (Tallinn: Eesti Klassikakirjastus, 2001), 145 .

50 Stephen Friar, The Sutton Companion to Churches (Stroud: Sutton Publishing, 2003), 426. Tatsächlich wurden im Laufe der Zeit für diese Fensterchen sehr verschiedene Erklärungen angeboten. Beispielsweise sollen sie für das Beichten gedacht gewesen sein, wobei sich der Priester innerhalb der Kirche befan und der Beichtende außerhalb. Laut der sogenannten vulne-Theorie ist die Kirche Jesus Christus und die Öffnung erinnert an dessen Stichwunden. Vom Fenster aus ließen sich zur Osterzeit die Pessachkerzen liegenden Dorf das Klingen der Sanctus-Glocke zum Zeitpunkt der Elevation der Hostie zu hören is (Thomas Maude, Guided by a Stone-mason. Exploring the Cathedrals, Abbeys and Churches of Britain (London: Tauris Parke Paperbacks, 2010), 143-145).

51 Christine Kratzke, ,,Ausstrahlung und Ausblick. Hagioskope im mittelalterlichen Klosterkirchen der Zisterzienser und Zisterzienserinnen im architekturhistorischen und theologischen Kontext" Licht und Farbe in der miltelallerlichen Backsteinarchitekur des sudlichen Ostseeranms. Studien zur Backsteinarchitektur, Bd. VII (Berlin: Lukas Verlag, 2005), 93-96. Übrigens war ein Hagioskop besonders unter den Zisterziensern verbreitet. 
- weder in natura noch in der Fachliteratur. ${ }^{52}$ In Estland gab es dagegen wenigstens acht solcher Sakramentsnischen, zusätzlich zu der auf Worms noch die in Pühalep (Pühalepa), Joerden (Juuru), in der Revaler Olaikirche (Oleviste kirik), in Luggenhusen (Lüganuse), Haljall (Haljala), Jakobi (Viru-Jaagupi) und Maholm (Viru-Nigula). Im Falle der fünf letzteren können wir sicher sein, dass sie im 15. Jahrhundert eingebaut worden sind. Es ist außergewöhnlich glaubwürdig, dass auch die anderen in derselben Zeit eingerichtet worden sind. Wahrscheinlich wurde eine solche Lösung erstmals im Chorraum der Revaler Olaikirche umgesetzt, der um das Jahr 1425 fertiggestellt wurde. ${ }^{53}$

Die genannten, besonderen Sakramentsnischen hat wiederholt Villem Raam erwähnt, nach dessen Auffassung eine solche Lösung es „ermöglichte, die Hostie auch den draußen Befindlichen zu exponieren“. ${ }^{54}$ Mit anderen Worten war die Sakramentsnische ausgestattet mit einem Hagioskop. Dennoch erscheint eine solche Interpretation als fragwürdig. Die Mehrheit dieser Öffnungen befindet sich für einen draußen stehenden Menschen in zu großer Höhe - in Haljal sogar in mehr als 3 Metern. Damit musste zum Ansehen der Hostie eine ordentliche Leiter zur Hand sein. Nach Auffassung des Verfassers dient der genannte Schacht nicht als eine Gucköffnung sondern stattdessen als Lichtöffnung. ${ }^{55}$ Die Frage besteht nicht darin, wie ein Raum oder ein Raumbereich besser ausgeleuchtet wird. In diesem Zusammenhang ist die Rede von der im 12. Jahrhundert herausgebildeten Doktrin (Begründer waren Abt Suger und Hugo von St. Victor), ${ }^{56}$ nach

52 Zum Thema sind in den letzten Jahren zwei umfangreiche Monografien erschienen: Achim Timmermann, Real Presence: Sacrament Houses and the Body of Christ, c. 1270-1600 (Turnhout: Brepols, 2009); Justin E. A. Kroesen, Die mittelalterliche Sakramentsnische auf Gotland (Schweden): Kunst und Liturgie (Petersberg: Imhof, 2004). Der in diesem Text zu untersuchende Typ der Sakramentsnische wird in ihnen nicht erwähnt.

53 Rasmus Kangropool, „Oleviste kirik“, Eesti arhitektuur 1. Tallinn (Tallinn: Valgus, 1993), 107.

54 Villem Raam, „Viru-Jaagupi kirik“, Eesti Arhitektuur 3. Harjumaa, Järvamaa, Raplamaa, LääneVirumaa, Ida-Virumaa (Tallinn: Valgus, 1997), 162. Eine ebensolche Erklärung wurde auch für die Sakramentsnischen in Haljall und Maholm vorgebracht (op. cit., 131, 163).

55 Diese Funktion wurde erstmals angeboten von: Kaur Alttoa, „Juuru Mihkli kirik“, Eesti Kirik, 30.03 1994. Diesen Standpunkt hat im Folgenden Kersti Markus akzeptiert (Kersti Markus, Rapluma kirikud (Tallinn: Muinsuskaitseamet, 2002), 27).

56 Otto von Simson, The Gothic Cathedral. Origins of Gothic Architecture and the Medieval Concept of Order (New York: Harper \& Row, 1964), 50-55; Erwin Panofsky, „Abbot Suger of St. Denis", Meaning in the Visual Arts. Papers in and on Art History (New York: Doubleday \& Company,
126-128. der Licht Gott entspricht und dieses Licht auch Gottes Attribut ist. Also werden die in der Sakramentsnische aufzubewahrenden Hostien (Corpus Christi) im vorliegenden Fall nicht nur von der obligatorischen Kerze oder Lampe beleuchtet, sondern auch noch durch natürliches Licht, also von Gott selbst. Dieses Thema verdiente eine gründlichere Behandlung, im Moment begrenzen wir uns einzig mit seiner Markierung. Fügen wir bezüglich der in dieser Form gestalteten Sakramentsnische noch einen rein praktischen Aspekt hinzu. Die Mehrheit der Schächte dieser Sakramentsnischen in Estland öffnen sich diagonal nach oben. Sollte es sich um Gucköffnungen handeln, wäre es erheblich günstiger diese horizontal einzubauen oder selbst nach unten gerichtet: so wäre die Hostie nicht nur besser sichtbar, sondern auch gegen mögliches Regenwasser deutlich besser geschützt.

\section{FAZIT}

Im momentanen Stadium der Forschung ist das Bild der Baugeschichte von St. Olai ausgesprochen lückenhaft. Im Mittelalter wurde einzig der Chorraum fertiggestellt, weil das geplante Langhaus aus Stein nicht gebaut wurde. Die Traditionen der Zisterzienser folgend diente die Domkirche zu Hapsal des Bistums Ösel-Wiek als unmittelbares Vorbild für die östliche Wand des Chorraums. Offensichtlich ist der Chor oder sind wenigstens dessen Wände in den siebziger Jahren des 13. Jahrhunderts fertiggestellt worden. Das Gewölbe des Chors und seine Malereien warten noch auf eine tiefere Analyse. Irgendwann später wurde der östlichen Wand des Chorraums eine Sakramentsnische mit einem Beleuchtungsschacht eingebaut. Solch eine Lösung war im 15. Jahrhundert ausgesprochen verbreitet in Nordestland. Dem Verfasser fehlen Angaben über das Vorhandensein von derartigen Sakramentsnischen irgendwo sonst im Abendland. 
Kaur Alttoa: Notes On The Building Of St Olaf's Church ON VORMSI ISLAND

Keywords: Church Architecture Of Oesel-Wiek; Haapsalu Cathedral; Cistercian Motifs In The Medieval Architecture Of Estonia; Hagioscope; Sacrament Niche

\section{SUMMARY}

Vormsi is a small island that belonged to the Oesel-Wiek bishopric during the Middle Ages. There is a church on the island that is dedicated to St Olaf, the Norwegian king who was undoubtedly the most popular saint among the Scandinavians. A short article written by Villem Raam in the anthology Eesti Arhitektuur (Estonian Architecture, 1996) is the only one worth mentioning that has appeared to date on the architectural history of the Vormsi church.

The Vormsi church is comprised of a sanctuary and nave. Only the sanctuary was completed during the Middle Ages, and the stone nave was not completed until 1632. During the restoration of the church between 1989 and 1990, fragments were found of the foundation of the wooden church that predated the stone one. It is possible that the wooden church was utilised throughout the Middle Ages as a congregation room.

Currently, it is believed that the Vormsi sanctuary was built during the $15^{\text {th }}$ century. This dating is based on the pyramid-shaped vault consoles - a similar shape also appears in the chapel of the gate tower in the Padise Cistercian monastery. Actually, the Padise consoles have been reused. Their original location is unknown and their completion is impossible to date even within the time frame of a century.

The most significant is the eastern wall of the Vormsi sanctuary, where a spacious niche with pointed arch is located. This Cistercian composition was also used in the Haapsalu Cathedral and apparently that was the model for the Vormsi church. The Haapsalu Cathedral is a surprisingly simple single-nave church with three bays. The church has richly decorated capitals on its wall pillars, on which both Romanesque and Early Gothic motifs have been used. At least some of the capitals have been hewn by a master who previously worked on the construction of the capital hall in the Riga Cathedral. The northern section of the Haapsalu Cathedral was apparently built in the 1260s. In the vicinity of Riga there is a church with a floor plan that is an exact counterpart to the one in Haapsalu - the Holme / Martinsala Church that dates back to about the $13^{\text {th }}$ century Considering both the floor plan and the sculptured decorations, it is believable that the designers and builders of the Haapsalu Cathedral came from the Riga environs.

Pärnu is also on the Riga-Haapsalu route. Actually, two towns existed there during the Middle Ages. For a short time, Old-Pärnu on the right bank of the river had been the centre of the Oesel-Wiek bishopric before Haapsalu. However, the left bank of the river was controlled by the Livonian Order. There is very little information about the OldPärnu Cathedral that was completed around 1251 and destroyed by the Lithuanians in 1263. However, one thing is known - it also had a single-nave with three bays. There is no information about the design of the eastern wall of the cathedral. However, the sanctuary of St Nicholas' Church in New-Pärnu had an eastern niche similar to the one in Haapsalu. It is not impossible that the motif was borrowed from the cathedral across the river or its ruins. Attention should also be paid to the fact that the design of the northern and southern walls in the sanctuary of Pärnu's St Nicholas' Church are similar to the Vormsi church. Therefore, there is no doubt that these two sanctuaries are architecturally and genetically related. Apparently the Vorms sanctuary was built immediately or soon after the completion of the Haapsalu Cathedral - not later than 1270. It is not impossible that the vaults were constructed sometime later.

The vault painting in the Vormsi sanctuary is probably inspired by the "paradise vaults" in Gotland. The Vormsi painting is strikingly primitive. In Estonia, this primitive style can also be seen in the churches in Ridala and Pöide.

There is a squint (hagioscope) on the southern wall of the Vormsi church sanctuary, and an unusual sacrament niche with a light shaft in the eastern wall. This does not date back to the time when the sanctuary was built, but was added later. There have been at least eight such sacrament niches in Estonia, most of which were built in the $15^{\text {th }}$ century. 


\section{CV}

Kaur Alttoa (b. 1947) has been a long-time scholar and teacher of art history at the University of Tartu and he is one of the foremost specialists of the history of medieval architecture in the Baltic region. His objects of interest have included both medieval fortresses and sacral buildings. Among his major contributions stands out the restoration and study of the St John's Church in Tartu, which was also published as a monograph in 2011. 